\title{
Regeneration of plants from alginate-encapsulated shoots of Rhododendron dalhousiae Hook. F.
}

\section{K.K. Singh ${ }^{*}$ and Bhusan Gurung}

G.B. Pant Institute of Himalayan Environment and Development, Sikkim Unit, Pangthang, Post Box 24 Gangtok, East Sikkim-737 101, INDIA

"Corresponding author. E-mail: singhkk20@yahoo.com

\begin{abstract}
A method has been developed for plant regeneration from alginate-encapsulated nodal segments of Rhododendron dalhousiae. Shoot tips collected from in vitro proliferated shoots were used for synthetic seed production. For encapsulation, nodal segments were mixed with MS medium supplemented with $3 \%$ sodium alginate and incubated with calcium chloride $(60 \mathrm{mM})$. The maximum frequency $(69 \%)$ of conversion of encapsulated shoot tips into plantlets was achieved on MS medium containing $25 \mu \mathrm{M}$ 2-isopentenyladenine (2iP) along with additive such as, $100 \mathrm{mg} \mathrm{L}^{-1}$ polyvinyl pyrrolidone (PVP), $100 \mathrm{mg} \mathrm{L}^{-1}$ ascorbic acid, $10 \mathrm{mg} \mathrm{L}^{-1}$ citric acid. The presence of $2 \mathrm{iP}(25 \mu \mathrm{M})$ with IAA $(0.6 \mu \mathrm{M})$ improved re-generation. Amongst the two gelling agents used higher shoot proliferation as well as better growth were observed in cultures grown on Agar in comparison to Phytagel medium. Encapsulated nodal segments stored at $4^{\circ} \mathrm{C}$ for 25 days also showed successful conversion, followed by development into complete plantlets when returned to regeneration medium. Liquid medium was superior over solid medium for root formation and growth. IBA $(1.0 \mu \mathrm{M})$ was more effective than other auxins for root induction. Plantlets with developed shoot and roots were hardened off to survive ex vitro conditions and successfully established in greenhouse. Possibility of direct sowing of synthetic seeds in the soil was also examined.
\end{abstract}

Keywords: Rhododendron dalhousiae, Encapsulation, Multiple shoot, In vitro propagation, Sikkim Himalaya

\section{INTRODUCTION}

All the species of Sikkim Himalaya rhododendron plants have the potential of commercial value. The genus Rhododendron is represented by eighty species in India (Gamble, 1936; Cowan and Cowan, 1938; Pradhan and Lachungpa, 1990; Bhattacharyya and Sanjappa, 2008) and is one of the most neglected groups of plants in terms of scientific inquiry so far in the Indian context. More than $90 \%$ of the world's natural population of rhododendrons are found in the Himalayan region. The regeneration status in the form of available seedlings/saplings is very poor for many of the rhododendrons (Kumar et al., 2005; Singh et al., 2003; Singh, 2009; Singh and Gurung, 2009). Micropropagation is more efficient than cutting propagation for this species.

The production of synthetic seeds or artificial seeds by encapsulation of vegetative propagules has become potentially cost effective for mass propagation of elite plant species. The advantages of using artificial seeds include ease of handling, transportation and potential storage, higher scale-up potential and low cost of production and subsequent propagation (Murashige, 1978; Nino and Sakai, 1992; Prewein and Wilhelm, 2003; Redenbaugh, 1993 and Singh, 2008). No other reports on tissue culture of this species have been provided to date.
In the present study, the encapsulation of nodal cuttings of R. dalhousiae in calcium alginate beads and conversion of encapsulated nodal segments into plantlets have been reported. In addition, the influence of low temperature storage on the viability of alginateencapsulated nodal segments has also been attempted. The possibility of direct sowing of synthetic seeds in the soil has also been examined.

\section{MATERIALS AND METHODS}

Plant materials and explant preparation: Mature seeds of Rhododendron. dalhousiae Hook. F. (local Name Lahare Chimal as known in Sikkim) were collected during October-November from the Arboratum, Pangthang, East Sikkim. Seeds were thoroughly washed with a detergent (Tween $-80 ; 1.0 \%$, v/v; $20 \mathrm{~min}$ ), and surface disinfected with an aqueous solution of mercuric chloride $(0.15 \%$; $\mathrm{w} / \mathrm{v} ; 3 \mathrm{~min}$ ) before use. Following washings (3 times) with autoclaved double distilled water under aseptic conditions, these were inoculated onto MS (Murashige and Skoog, 1962) nutrient medium containing $0.8 \%$ (w/v) agar. Shoot tip portions $(0.5 \mathrm{~cm})$ were carefully excised from seedlings, under aseptic conditions, and subcultured on MS medium containing $25 \mu \mathrm{M}$ isopentenyladenine (2iP) along with additives $100 \mathrm{mg} \mathrm{L}^{-1}$ polyvinyl pyrrolidone (PVP), $100 \mathrm{mg} \mathrm{L}^{-1}$ ascorbic acid and $10 \mathrm{mg} \mathrm{L}^{-1}$ citric acid. 
Table 1. Effects of different media/substrates supplemented with $25 \mu \mathrm{M} 2 \mathrm{iP}$ and $0.6 \mu \mathrm{M}$ IAA on conversion of encapsulated nodal segments of R. dalhousiae Hook. f. after 12 weeks of culture.

\begin{tabular}{lcc}
\hline M edia/substrate & $\begin{array}{c}\text { Conver sion of encapsulated shoot tips } \\
\text { into plantlets }(\%) \pm \text { SE }\end{array}$ & $\begin{array}{c}\text { Plant regeneration from non-encapsulated } \\
\text { shoot tips }(\%) \pm S E\end{array}$ \\
\hline AM + Agar $(0.8 \%)$ & $42.75 \pm 3.06$ & $43.00 \pm 1.45$ \\
AM + Phytagel (0.3\%) & $60.75 \pm 0.67$ & $63.00 \pm 1.76$ \\
$1 / 2$ MS + Agar (0.8\%) & $51.75 \pm 3.46$ & $53.75 \pm 1.20$ \\
1/2 MS + Phytagel (0.3\%) & $49.25 \pm 2.19$ & $54.50 \pm 2.31$ \\
MS + Agar (0.8\%) & $69.50 \pm 2.65$ & $82.00 \pm 1.76$ \\
MS + Phytagel (0.3\%) & $64.00 \pm 1.76$ & $65.50 \pm 1.76$ \\
LSD at the 5\% level & 9.5 & 10.2 \\
\hline
\end{tabular}

Values represent means \pm SE. Each treatment consisted of 20 replicates and the experiment was repeated twice.

Nodal segments approx. 3-4 mm long were excised for encapsulation.

Encapsulation: Encapsulation of nodal segment was performed by preparing 3\% (w/v) sodium alginate (Merck India $\mathrm{Ltd}$ ) solution in $\mathrm{CaCl}_{2}$ free MS medium containing $3 \%$ sucrose $(w / v)$ without growth regulators. For encapsulation, $60 \mathrm{mM}$ Calcium chloride solution was prepared in double distilled water. Sodium alginate and $\mathrm{CaCl}_{2} \cdot 2 \mathrm{H}_{2} \mathrm{O}$ solution were sterilized by autoclaving at $121^{\circ} \mathrm{C}$ for $15 \mathrm{~min}$ after adjusting the $\mathrm{pH}$ to 5.6. Encapsulation was accomplished by mixing the nodal segments into the alginate solution and dropping these into the $\mathrm{CaCl}_{2} \cdot 2 \mathrm{H}_{2} \mathrm{O}$ solution. Calcium alginate beads were incubated in the $\mathrm{CaCl}_{2}$ solution for 30 min. Encapsulated shoot tips were washed three times with sterilized doubledistilled water.

Conversion of encapsulated shoot tips into complete plantlets: For conversion into complete plantlets under in vitro conditions encapsulated shoot tips were directly planted onto conical flak $(250 \mathrm{ml})$ containing AM (Anderson, 1984), $1 \frac{1}{2}$ MS, MS culture media. The media was gelled with agar $(0.8 \%)$ or phytagel $(0.3 \%)$ supplemented with $25 \mu \mathrm{M} 2 \mathrm{iP}, 0.6 \mu \mathrm{M}$ IAA along with additives (100 mg L $\mathrm{mVP}^{-1}$ PV $100 \mathrm{mg} \mathrm{L}^{-1}$ ascorbic acid and 10 $\mathrm{mg} \mathrm{L} \mathrm{L}^{-1}$ citric acid). The $\mathrm{pH}$ of the media was adjusted at 5.6 prior to the addition of gelling agent and autoclaving at $121^{\circ} \mathrm{C}$ for 15 minutes at $1.05 \mathrm{~kg} / \mathrm{cm}^{2}$ pressure. All cultures were maintained at $23^{\circ} \mathrm{C} \pm 1{ }^{\circ} \mathrm{C}$ temperature under a $16 \mathrm{~h}$ photoperiod with a photosynthetic photon flux density of $60 \mathrm{mmol} \mathrm{m} \mathrm{m}^{-2} \mathrm{~s}^{-1}$, provided by cool-white fluorescent light and $60 \%$ relative humidity. The cultured were transferred to fresh medium after 4 week intervals.

Ger mination of encapsulated shoot tips in ster ile soil: To test the germination of synseeds in soil, the freshly encapsulated shoot tips in 3\% sodium alginate following the method described previously were sown in autoclaved fresh peat moss and soil (1:3). Percentage of germination was recorded after one month of sowing.

L ow temperature storage: Encapsulated and nonencapsulated shoot tips were stored for 15, 30 and 50 days at $4^{\circ} \mathrm{C}$ in the dark. After each storage period, encapsulated and non- encapsulated shoot tips were cultured on MS medium The media was gelled with phytagel $(0.3 \%)$ supplemented with $25 \mu \mathrm{M} 2 \mathrm{iP}, 0.6 \mu \mathrm{M}$ IAA along with additives (100 $\mathrm{mg} \mathrm{L}^{-1} \mathrm{PVP}, 100 \mathrm{mg} \mathrm{L}^{-1}$ ascorbic acid and $10 \mathrm{mg} \mathrm{L}^{-1}$ citric acid) and $3 \%$ sucrose used for conversion into plantlets.

R ooting and acclimatization: For rooting, shoots of 2-4 $\mathrm{cm}$ length were isolated from the shoot clump and transferred to MS medium containing 1.0 $\mu \mathrm{M}$ IBA (optimum concentration) was used for filter paper bridge technique using liquid medium. After rooting, regenerated plantlets were washed carefully and planted in plastic pots $(125 \mathrm{ml})$ containing autoclaved fresh peat moss and soil (1:3). After 1 month, surviving plants were transferred to pots containing normal garden soil and maintained in greenhouse.

Experimental design and data analysis: Percentage

Table 2. Effects of different durations of storage at $4^{\circ} \mathrm{C}$ on the conservation of encapsulated or non-encapsulated nodal segments of R. dalhousiae Hook. F. on MS medium.

\begin{tabular}{lcc}
\hline Storage duration (d) & $\begin{array}{c}\text { Conversion of encapsulated shoot tips into } \\
\text { plantlets }(\%) \pm \text { SE }\end{array}$ & $\begin{array}{c}\text { Plant regeneration from non- } \\
\text { encapsulated shoot tips }(\%) \pm \text { SE }\end{array}$ \\
\hline 0 & $72.75 \pm 3.06$ & $77.25 \pm 2.31$ \\
15 & $67.00 \pm 1.76$ & $52.00 \pm 3.52$ \\
25 & $55.50 \pm 3.06$ & $30.75 \pm 3.71$ \\
35 & $43.00 \pm 3.05$ & $18.75 \pm 2.07$ \\
50 & $34.75 \pm 2.40$ & $9.50 \pm 1.33$ \\
\hline LSD at the 5\% level & 10.2 & 12.6 \\
\hline
\end{tabular}

Values represent means \pm SE. Each treatment consisted of 20 replicates and the experiment was repeated twice. Data were recorded after 8 weeks of culture. 


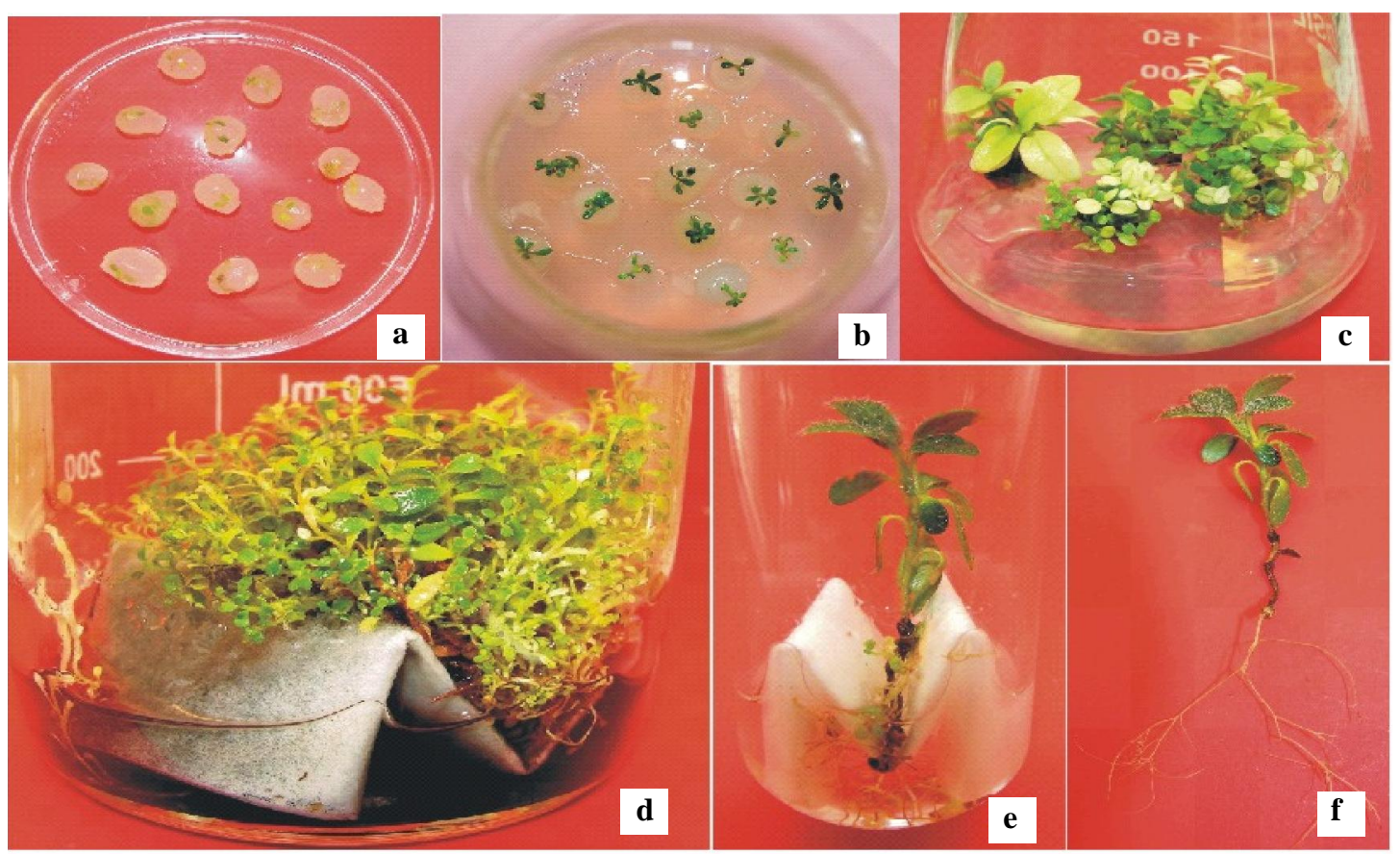

Fig. 1. In vitro plant regener ation from encapsulated shoot tips of R. dalhousiae H ook. F. a. bead formed by the encapsulation of shoot tips using $3 \%$ Sodium al ginate and $60 \mathrm{mM} \mathrm{CaCl}_{2} \mathrm{H}_{2} \mathrm{O}$. b. Ruptured beads showing sprouting shoots on $\mathrm{M} \mathrm{S}$ medium after 8 weeks of culture. c. Regenerated plantl ets from encapsulated nodal segment on M S medium supplemented with $0.8 \%$ Agar after 12 weeks of culture. $d, e$, f. Root induction from shoot tips on M S medium supplemented with $1.0 \mu \mathrm{M}$ IBA.

response of conversion of stored shoot tips into plantlets was recorded after 8 week of culture. The conversion of encapsulated shoot tips was determined on the basis of differentiation of shoot with apparent leaves. In all experiments, each treatment consisted of 20 replicates and each experiment was repeated twice. Standard error of the mean was calculated. Least significance difference (LSD) at $\mathrm{P}<0.05$ level was calculated following the method of Snedecor and Cochran (1967). All plant growth regulators (PGRs) used were from Sigma Chem. Company, USA.

\section{RESULTS AND DISCUSSION}

Freshly encapsulated shoot tips in $3 \%(w / v)$ sodium alginate $60 \mathrm{mM}$ Calcium chloride exhibited shoot growth initiation after second week of culture on $1 / 2 \mathrm{MS}$, MS and AM supplemented with $25 \mu \mathrm{M} 2 \mathrm{iP}$ and various gelling agents like agar $(0.8 \%)$ and phytagel $(0.3 \%)$ along with additives (100 $\mathrm{mg} \mathrm{L}^{-1} \mathrm{PVP}, 100 \mathrm{mg} \mathrm{L}^{-1}$ ascorbic acid and 10 $\mathrm{mg} \mathrm{L}^{-1}$ citric acid). Highest yield of shoots was obtained with $25 \mu \mathrm{M} 2 \mathrm{iP}$ on MS medium with Agar in comparison to cultures grown on phytagel media. MS medium supplemented $25 \mu \mathrm{M} 2 \mathrm{iP}$ with $0.8 \%$ Agar gave the maximum frequency (70\%) of conversion of encapsulated shoot tips into plantlets (Table 1; Fig. 1a-c). Conversion into complete plantlets was achieved after 8 weeks of culture on this medium. It was observed that non encapsulated shoot tips possessed higher conversion than encapsulated shoot tips under the same culture conditions (Table 1). The encapsulated explants failed to respond on hormone-free, basal MS medium. The presence of $2 \mathrm{iP}(25 \mu \mathrm{M})$ with IAA $(0.6 \mu \mathrm{M})$ improved regeneration. Shoots were phenotypically normal with distinct nodes and internodes.

The shoot proliferation efficiency of the encapsulated nodal segments stored at low temperature $\left(4^{\circ} \mathrm{C}\right)$ for different time periods $(15,25,35$ and 50 days) was tested. Encapsulated and non-encapsulated nodal segments sprouted after 2 weeks of culture on MS medium and sprouting was only slightly higher (77\%) in nonencapsulated buds compared to the encapsulated ones $(73 \%)$.When storage duration exceeded 25 days, encapsulated shoot tips significantly decreases the number of plantlets (Table 2). Non-encapsulated nodal segment had much lower survival rate in this study which may be due to the immersed nature of small clumps in the medium. The decline in plant recovery from stored encapsulated nodal segments may be due to both oxygen deficiency in the calcium alginate bead and its rapid drying (Redenbaugh et al., 1991). Visual observations showed that shoot tips progressively turned brown during storage. Highest regeneration percentage of stored nodal segments of $R$. dalhousiae indicated that at $4^{\circ} \mathrm{C}$ is optimum for short term storage. This indicated that encapsulated matrix serves as a reserve of nutrients to the encapsulated explants for regeneration (Bapat and Rao, 1992; Castillo et al., 1998; Singh, 2008).

Rooting was successfully induced in the regenerated shoot when transferred to MS medium containing activated charcoal $(1.0 \%, \mathrm{w} / \mathrm{v})$ and $1.0 \mu \mathrm{M}$ IBA. IBA was the only hormone effective in induction of roots in 


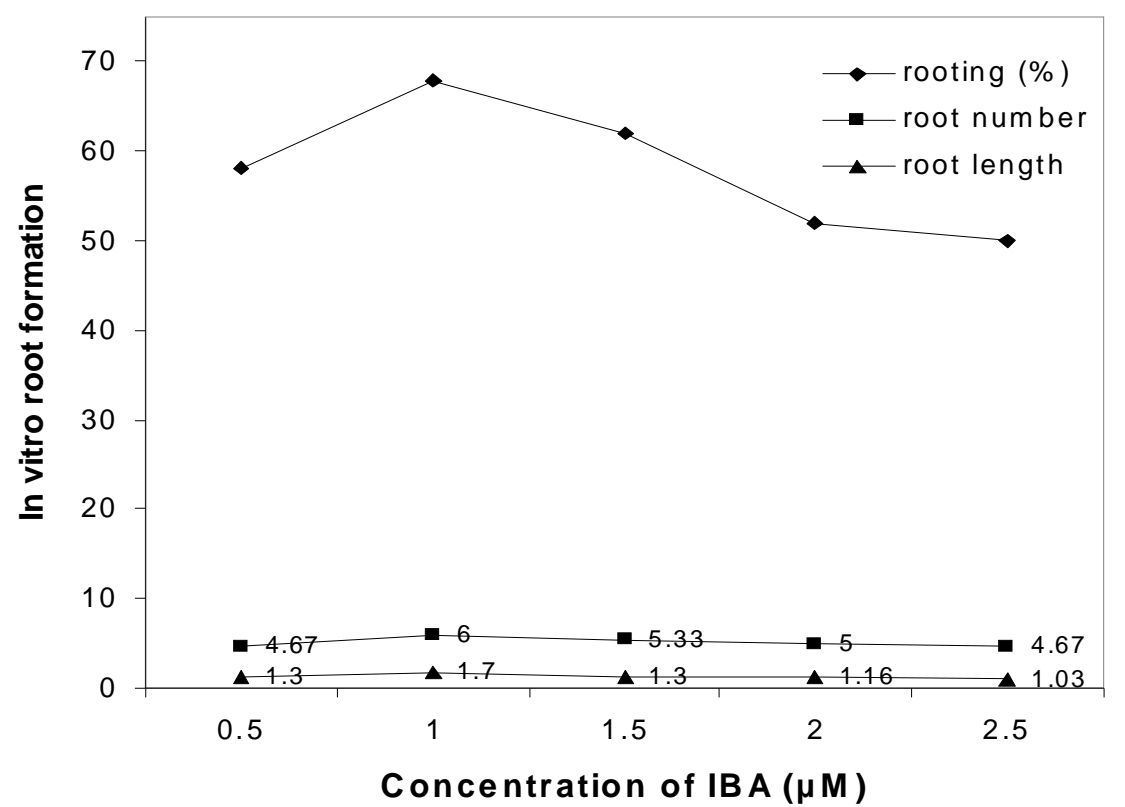

Fig. 2. Effect of MS medium with different concentration of IBA on the mean percentage of roots response ( $\downarrow$, the mean root number $($ ), the mean root length $(\mathrm{cm})($ ). D ata were recorded 9 weeks after transfer to liquid-M S medium.

regenerated shoots (Fig. 2). Lower concentration of IBA inefficient for rooting and higher concentration showed inhibition of roots and initiation of compact nonembryogenic callus from shoot. The roots were thick and healthy and new shoots continued to regenerate from the rooted basal portion of the plant on prolonged cultured (Fig. 1 d-f). No any adverse effect was observed on the rooting of micro-shoots derived from encapsulated beads at $4^{\circ} \mathrm{C}$. Plantlets with well developed roots and shoots were transferred in thermocole cups containing a mixture of autoclaved fresh peat moss and soil (1:3) and placed for hardening under high relative humidity $(80 \%)$ in the mist chamber of a greenhouse $\left(25^{\circ} \mathrm{C}\right)$. After one month these were planted in polythene bag containing normal garden soil, $86 \%$ survived under green house conditions (Fig. 3 a, b). Encapsulated buds were also placed on autoclaved fresh peat moss and soil (1:3) moistened with MS medium, to test the emergence of shoot from them. A very low percent of encapsulated nodal segments prepared in MS medium sprouted after 30 days, when placed on autoclaved fresh peat moss and soil (1:3) and kept under culture lab conditions, but turned brown thereafter.

The present study reports successful implementation of artificial seed of R. dalhousiae. Preserving the viability of encapsulated shoot tips even after 15-25 days of storage at low temperature offers the possibility of using synthetic seed technology for short-term germplasm conservation of this important plant species. Such work could be useful as nodal delivery system for germplasm

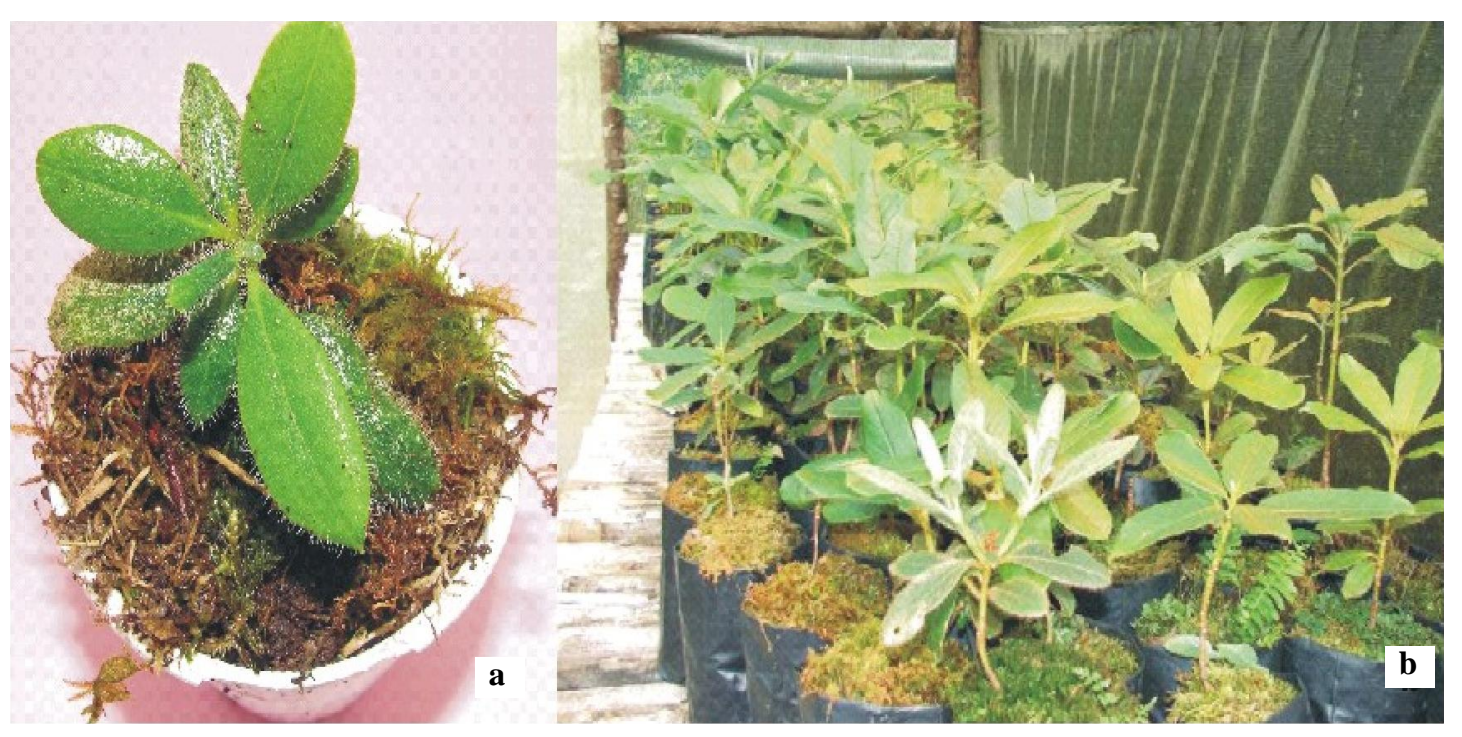

Fig. 3. Regenerated R. dalhousiae H ook. F. with well developed shoots and roots. a and b. Three month-old acclimatized plants derived from encapsulated nodal segments in green house. 
exchange and storage for germplasm preservation, micropropagation of rhododendron spp.

\section{ACKNOWLEDGEMENTS}

Authors are highly grateful to Dr. L.M.S. Palni, Director, G.B. Pant Institute of Himalayan Environment and Development, Almora, for availing all kinds of laboratory and institutional facilities. Council of Scientific and Industrial Research, New Delhi. India, gave financial assistance in the form of a Project. Department of Forests, Environment and Wildlife Management, Government of Sikkim is also duly acknowledged for cooperation. Mohan Kumar Thapa and Sunil are thanked for their assistance.

\section{REFERENCES}

Anderson, W.C. (1984). A revised tissue culture medium for shoot multiplication of rhododendron. J ournal of the American Society for H ort. Sci., 109: 343-347.

Bapat, V.A. and Rao, P.S. (1992). Plantlet regeneration from encapsulated and non-encapsulated desiccated somatic embryos of forest tree, sandalwood (Santalum album L). J . Plant Biochem. Biotechnol., 1: 109-113.

Bhattacharyya, D. and Sanjappa, M. (2008). Rhododendron habitats in India. J. Amer. Rhodo. Soc., 62: 14-18.

Castillo, B., Smith, M.A.I. and Yadava, U.I. (1998). Plant regeneration from encapsulated somatic embryos $\mathrm{C}$ arcia papaya I. Plant Cell Report., 17: 172-176.

Cowan, A.M. and Cowan, J.M. (1938). Trees of the Northern Bengal, Calcutta.

Gamble, J. (1936). A Manual of Indian Timbers. Sampson Low, Marston \& Co., London.

Kumar, S., Rai, L.K., Singh, K.K and Bajpai, U. (2005). Spermoderm pattern in seeds of rhododendron in Sikkim Himalaya, India-1. SEM studies. Phytomorphology, 55(1\&2): 01-08.

Murashige, T. (1978). The impact of plant tissue culture on agriculture. In: Thorpe, T., ed. Frontiers plant tissue cultures. International Association for plant tissue culture: University of Calgary, Alberta, 15-26.

Murashige, T. and Skoog, F. (1962). A revised medium for rapid growth and bioassays with tobacco tissue cultures. Physiol. Planta., 15: 473-497.

Nino T. and Sakai, A. (1992). A Cryopreservation of alginatecoated in vitro grown shoot tips of apple, pear and mulberry. Plant Sci., 87: 199-206.

Pradhan, U.C. and Lachungpa, S.T. (1990). Sikkim-Himalayan Rhododendrons. Primulaceae Books, Kalimpong, West Bengal.

Prewein, C. and Wilhelm, E. (2003). Plant regeneration from encapsulated somatic embryos of pedunculate oak ( $Q$ uercus robur L.). In vitro Cell. D ev. Biol.-Plant., 39: 613-617.

Redenbaugh, K. (1993). Synseeds: application of synthetic seeds for crop improvement. Boca Raton, USA: CRC Press.

Redenbaugh, K., Fujii, J. A., Slade, D., Viss, P. R. and Kossler, M. E. (1991). Artificial seeds-encapsulated embryos. In: Bajaj, Y. P. S., ed. Biotechnology in agriculture and forestry, High technology and micropropagation I, vol. 17. Berlin, Heidelberg: Springer-Verlag., 395-416.

Singh, K.K. (2009). Notes on the Sikkim Himalayan Rhododendrons: a taxa of great conservation importance. Turk J B ot., 33: 305-310.

Singh, K.K. (2008). In Vitro plant regeneration of an endangered Sikkim Himalayan rhododendron (R. maddeni Hook. f.) from alginate-encapsulated shoot tips. Biotechnol., 7(1): 144-148.

Singh, K.K. and Gurung, B. (2009). In vitro propagation of R. maddeni Hook. f. an endangered rhododendron species of Sikkim Himalaya. Notulae Botanicae Horti Agrobotanici Cluj-Napoca., 37: 79-83.

Singh, K.K., Kumar, S., Rai, L.K. and Krishna, A.P. (2003). Rhododendron conservation in Sikkim Himalaya. C urr. Sci., 85 (5): 602-606.

Snedecor, G.W., Cochran, W.G. (1967). Statistical Methods. Oxford and IBH publishing Co., New Delhi, 593 pp. 